\title{
Mentorship Experiences of Doctoral Students: Understanding Desired Attributes of Doctoral Student Mentors
}

\author{
Stephanie M. Singe \\ University of Connecticut - Storrs, stephanie.m.singe@uconn.edu \\ Lauren Sheldon \\ University of Connecticut, lauren.sheldon@uconn.edu \\ Kelsey Rynkiewicz \\ University of Connecticut, kelsey.rynkiewicz@uconn.edu \\ Ciara Manning \\ University of Connecticut, ciara.manning@uconn.edu \\ Erica Filep \\ University of Connecticut, erica.filep@uconn.edu \\ See next page for additional authors
}

Follow this and additional works at: https://nsuworks.nova.edu/ijahsp

Part of the Higher Education Commons, and the Medicine and Health Sciences Commons

\section{Recommended Citation}

Singe SM, Sheldon L, Rynkiewicz K, Manning C, Filep E, Zuk E, et al. Mentorship Experiences of Doctoral Students: Understanding Desired Attributes of Doctoral Student Mentors. The Internet Journal of Allied Health Sciences and Practice. 2021 Jan 01;19(1), Article 13.

This Manuscript is brought to you for free and open access by the College of Health Care Sciences at NSUWorks. It has been accepted for inclusion in Internet Journal of Allied Health Sciences and Practice by an authorized editor of NSUWorks. For more information, please contact nsuworks@nova.edu. 


\title{
Mentorship Experiences of Doctoral Students: Understanding Desired Attributes of Doctoral Student Mentors
}

\begin{abstract}
Background: Mentorship is a critical aspect of the professional development of the doctoral student who wishes to pursue a role in higher education. Continued understanding is needed regarding the needs of the doctoral student when it comes to mentorship. Purpose: The purpose of this study is to describe the needs of a doctoral student from their mentoring relationships, as they work towards their terminal degree. Methods: This is a descriptive, phenomenological qualitative research study within universities that offer doctoral education. One-on-one, semi-structured interviews were conducted using Zoom video conference technology. Each interview, after transcribed, was analyzed following the step-wise approach of a phenomenological study. Credibility was established by 1) research triangulation, 2) bracketing/ reflexivity, and 3) peer review. Results: Twelve doctoral students ( 7 females, 5 males) who were enrolled in doctoral programs with a focus on allied health or exercise science completed the Zoom interviews. Our participants were an average age of 283 years, and all twelve had graduate assistantship positions in association with their doctoral programs. Three main themes materialized from the data analyses including 1) guided autonomy, 2) humanistic nature, and 3) professional advocate. Doctoral students want guidance to develop the technical skills necessary for success by providing opportunities to perform with the chance to gain feedback. Mentors were identified as needing to demonstrate humanistic qualities that were rooted in being interpersonal. The importance of a mentor serving as a professional advocate to help the student grow and develop as a professional was also discussed. Conclusions: Doctoral students need their mentors to demonstrate both personal and professional attributes in the mentor relationship. Specifically, they are looking for guidance and feedback through independent learning, as well as a mentor who values them, is relatable, and is invested in their development as a professional.
\end{abstract}

\section{Author Bio(s)}

Stephanie M. Singe, PhD, ATC, FNATA* is an associate professor in the Department of Kinesiology at the University of Connecticut.

Lauren Sheldon, MS, ATC* is graduate student in the Department of Kinesiology and a certified athletic trainer.

Kelsey M. Rynkiewicz, MS, MSHA, ATC, NREMT* is graduate student in the Department of Kinesiology and a certified athletic trainer.

Ciara Manning* is master's student in the Department of Kinesiology.

Erica M. Filep, MSEd, LAT, ATC* is graduate student in the Department of Kinesiology and a certified athletic trainer.

Emma Zuk, MS, ATC*is graduate student in the Department of Kinesiology and a certified athletic trainer.

Caitlin B. Hargrave, LAT, ATC* is master's student in the Department of Kinesiology and a certified athletic trainer.

\section{Authors}

Stephanie M. Singe, Lauren Sheldon, Kelsey Rynkiewicz, Ciara Manning, Erica Filep, Emma Zuk, and Caitliin Hargrave 


\title{
TIJAHSP
}

The Internet Journal of Allied Health Sciences and Practice

Dedicated to allied health professional practice and education

Vol. 19 No. 1 ISSN 1540-580X

\section{Mentorship Experiences of Doctoral Students: Understanding Desired Attributes of Doctoral Student Mentors}

\author{
Stephanie M. Singe \\ Lauren Sheldon \\ Kelsey Rynkiewicz \\ Ciara Manning \\ Erica Filep \\ Emma Zuk \\ Caitlin Hargrave \\ University of Connecticut \\ United States
}

\begin{abstract}
Background: Mentorship is a critical aspect of the professional development of the doctoral student who wishes to pursue a role in higher education. Continued understanding is needed regarding the needs of the doctoral student when it comes to mentorship. Purpose: The purpose of this study is to describe the needs of a doctoral student from their mentoring relationships, as they work towards their terminal degree. Methods: This is a descriptive, phenomenological qualitative research study within universities that offer doctoral education. One-on-one, semi-structured interviews were conducted using Zoom video conference technology. Each interview, after transcribed, was analyzed following the step-wise approach of a phenomenological study. Credibility was established by 1) research triangulation, 2) bracketing/reflexivity, and 3) peer review. Results: Twelve doctoral students (7 females, 5 males) who were enrolled in doctoral programs with a focus on allied health or exercise science completed the Zoom interviews. Our participants were an average age of $28 \pm 3$ years, and all twelve had graduate assistantship positions in association with their doctoral programs. Three main themes materialized from the data analyses including 1) guided autonomy, 2) humanistic nature, and 3) professional advocate. Doctoral students want guidance to develop the technical skills necessary for success by providing opportunities to perform with the chance to gain feedback. Mentors were identified as needing to demonstrate humanistic qualities that were rooted in being interpersonal. The importance of a mentor serving as a professional advocate to help the student grow and develop as a professional was also discussed. Conclusions: Doctoral students need their mentors to demonstrate both personal and professional attributes in the mentor relationship. Specifically, they are looking for guidance and feedback through independent learning, as well as a mentor who values them, is relatable, and is invested in their development as a professional.
\end{abstract}

Keywords: mentorship, professional development, doctoral students 


\section{INTRODUCTION}

Mentorship is the primary mechanism whereby by an individual or newcomer becomes familiar with the role they intend to assume one day; and has been the focus on numerous research studies examining the socialization process of doctoral students and junior faculty as they acclimate into higher education. ${ }^{1}$ Mentorship has been classified as dynamic process that allows the newcomer the chance to gain the skills and knowledge that will help them succeed, but also the support they need to overcome the uncertainties than can accompany role learning and inductance. ${ }^{2}$

Mentoring is a critical aspect of doctoral education, as it helps provide the doctoral student chances to feel connected, acclimated, and integrated into their future role in higher education. ${ }^{3,4}$ The development of an effective mentoring relationship is a fundamental aspect of the socialization process as there is often an exchange of knowledge, sharing of past experiences, and facilitation of learning opportunities to help with professional and personal development.5-10 The professional socialization process is often described as a critical time when a novice individual gains valuable knowledge, skills, and experiences they will need to effectively transition into their future roles.

The relationship between the doctoral student (i.e. the mentee) and their mentor has been viewed historically as an indispensable aspect of the socialization process, particularly as it facilitates the student's degree completion along with professional and personal development. ${ }^{11}$ Mentorship has various definitions; however, at its grassroots, the relationship is a partnership between a more experienced individual (i.e. mentor) and a less experienced or novice individual (i.e. mentee),8,12,13 Although the relationship has been viewed as reciprocal and mutually beneficial, there is some expectation that the mentor is charged with facilitating the success of the mentee, as they possess the knowledge, skills, and experiences the mentee desires. Kram suggested that a mentor helps facilitate not only the career aspirations and development of their mentees, but also provides emotional and psychological support. ${ }^{14}$ This conceptual model of mentoring was confirmed by Yob and Crawford, who described mentoring to be characterized by academic/career and psychological functions. ${ }^{15}$ Within these functions of mentoring are attributes that are often described as either relational (i.e. cultivate an environment of mentoring, via feedback, guidance) or personal (i.e. specific to the individual mentor, often seen as interpersonal skills).

Because of the importance of the mentoring relationship, research has examined factors that are believed to support an effective mentoring relationship including ideal mentor qualities and functions. $5,10,16,17$ Fundamentally speaking, a mentor serves many roles (i.e. teacher, advisor, counselor, etc.); thus, the qualities that embody an ideal or effective mentor are rooted in competence, availability, interest, communication, and support. ${ }^{11,15,18}$ While there is an extensive understanding of mentoring within doctoral education, there is little research that examines the perspective of the doctoral student enrolled in an allied health related program, as they prepare to enter a faculty role. Although doctoral education is meant to indoctrinate the student to the generalities of the faculty role; gaining discipline specific training is also important for successful mentoring and socialization to the faculty role. Thus, our purpose was to better understand the mentoring experiences, particularly related to the doctoral students' needs from their mentors as they navigate their degree programs. Specifically, we sought to answer: 1) What attributes are doctoral students looking for in their mentors (i.e. ideal qualities)? and 2) What do doctoral students want out of their mentoring relationships from their mentors?

\section{METHODS}

\section{Research Design}

A phenomenological lens was used to learn more about doctoral students' needs and preferences in regard to their mentorship experiences while pursuing an academic degree. The phenomenological framework was best as it allowed us to learn from the lived experiences of our participants as doctoral students. ${ }^{19,20} \mathrm{It}$ is important to appreciate the perceptions of the participant while they live it as it gives context alongside a realistic lens in which to better understand the experience.

\section{Participants}

Using professional networking, we purposefully recruited doctoral students who were enrolled in a full-time academic doctoral degree program with an assistantship. We required our participants to have completed a minimum of three full academic semesters and to be in least their second year of study, be enrolled in an academic doctoral degree program (PhD, EdD), which requires inperson interactions for coursework, and the degree program be in an exercise science related field (i.e. allied health, rehabilitation science, etc.). We individually emailed known faculty advisors of doctoral students to gain access to our participant pool. After institutional review board approval was gained, we screened sixteen doctoral students, and twelve met our inclusion criteria. Data saturation was established at twelve, and recruitment ended.

Twelve doctoral students completed the interviews (7 females, 5 males). Our participants were an average age of $28 \pm 3$ years. All the participants identified having a current mentor that was guiding their doctoral studies, and the mentor was currently at the 
institution where they were being educated. All participants were enrolled in different higher education institutions across the eastern part of the United States.

Graduate assistantships were identified as research-based, with ten out of twelve participants having a research component to their position. A research component was summarized by facilitating research projects that supported their research interests or that of their mentor. Others had teaching-based or clinical-based (i.e. providing patient care) assistantships. A teaching-based assistantship included course instruction and other tasks associated with the facilitation of the teaching component of higher education; similar to a teaching-assistant role. Six out of twelve individuals held certifications as an athletic trainer (ATC); of those six, three were also dually credentialed as physical therapists and athletic trainers (DPT, ATC). A clinical-based assistantship involved medical care as either a physical therapist or athletic trainer using the credentials outlined previously. One participant held certification as a certified strength and conditioning specialist (CSCS). Table 1 displays the individual data for each participant.

Table 1. Individual Demographic Data

\begin{tabular}{|c|c|c|c|c|c|c|c|}
\hline Participant & Age & Sex & $\begin{array}{l}\text { Program \& } \\
\text { Field }\end{array}$ & $\begin{array}{l}\text { Year in } \\
\text { Program }\end{array}$ & $\begin{array}{l}\text { "Type" of } \\
\text { Graduate } \\
\text { Assistantship }\end{array}$ & Credentials & $\begin{array}{l}\text { Doctoral } \\
\text { Mentor Sex }\end{array}$ \\
\hline Melissa & 28 & $F$ & $\begin{array}{l}\text { PhD Exercise } \\
\text { Science }\end{array}$ & $3^{\text {rd }}$ & $\begin{array}{l}\text { Research } \\
\text { and } \\
\text { Teaching }\end{array}$ & ATC & $\mathrm{F}$ \\
\hline Jason & 26 & M & $\begin{array}{l}\text { PhD } \\
\text { Rehabilitation } \\
\text { Sciences }\end{array}$ & $2^{\text {nd }}$ & Research & PT & M \\
\hline Tyler & 29 & M & $\begin{array}{l}\text { PhD Exercise } \\
\text { Science }\end{array}$ & $2^{\text {nd }}$ & Teaching & ATC, PT & $M$ \\
\hline John & 35 & M & $\begin{array}{l}\text { PhD Teaching } \\
\text { and } \\
\text { Administration }\end{array}$ & $4^{\text {th }}$ & Teaching & ATC, PES & $\mathrm{F}$ \\
\hline Stella & 26 & $\mathrm{~F}$ & $\begin{array}{l}\mathrm{PhD} \\
\text { Kinesiology }\end{array}$ & $2^{\text {nd }}$ & Research & MS & $\mathrm{F}$ \\
\hline Manny & 25 & M & $\begin{array}{l}\text { PhD } \\
\text { Kinesiology }\end{array}$ & $2^{\text {nd }}$ & Research & MS & $\mathrm{F}$ \\
\hline Shirley & 33 & $F$ & $\begin{array}{l}\text { PhD } \\
\text { Kinesiology }\end{array}$ & $2^{\text {nd }}$ & $\begin{array}{l}\text { Research } \\
\text { and } \\
\text { Teaching }\end{array}$ & MS, CSCS & M \\
\hline Tim & 26 & M & $\begin{array}{l}\text { PhD } \\
\text { Microbiology }\end{array}$ & $2^{\text {nd }}$ & Graduate & MHS & M \\
\hline Katie & 28 & $F$ & $\begin{array}{l}\text { PhD } \\
\text { Kinesiology }\end{array}$ & $2^{\text {nd }}$ & Research & MS & M \\
\hline Julia & 28 & $F$ & $\begin{array}{l}\text { EdD Higher } \\
\text { Education }\end{array}$ & $3^{\text {rd }}$ & $\begin{array}{l}\text { Research } \\
\text { and } \\
\text { Teaching }\end{array}$ & $\begin{array}{l}\text { MS, LAT, } \\
\text { ATC }\end{array}$ & $F$ \\
\hline Josie & 26 & $F$ & $\begin{array}{l}\text { PhD Exercise } \\
\text { Science } \\
\text { Sports } \\
\text { Medicine } \\
\text { Focus }\end{array}$ & $3^{\text {rd }}$ & $\begin{array}{l}\text { Research } \\
\text { and } \\
\text { Teaching }\end{array}$ & MEd, ATC & M \\
\hline Abby & 30 & $F$ & $\begin{array}{l}\text { PhD } \\
\text { Rehabilitation } \\
\text { Sciences }\end{array}$ & $2^{\text {nd }}$ & $\begin{array}{l}\text { Graduate } \\
\text { and } \\
\text { Research }\end{array}$ & ATC, DPT & $M$ \\
\hline
\end{tabular}

Data Collection

\section{Instrumentation}

An initial brainstorm session was conducted amongst the research team $(n=7)$, which was guided by the literature and the purpose of the study. ${ }^{5}$ The research team included six graduate students who brought their own personal experiences with mentoring. Prior 
to the brainstorming session, each shared their personal philosophies and experiences in regard to mentoring, as a means to bring reflexivity to the study. ${ }^{20}$ The students identified having a mentor and had self-reported that mentoring had been a part of their socialization process. This was important to understand current perspectives and real-time perspectives of the mentoring relationship between a student and doctoral mentor. The final member of the research team was a seasoned qualitative researcher, with knowledge of the mentorship phenomenon and the socialization theoretical framework. All research members were currently all from the same institution, at the time of the data collection procedures.

A semi-structured interview guide was developed to provide structure for each interview session, as it would allow for consistency between each interview, yet allow for a more naturalistic dialogue between the researcher and the interview participant. The interview protocol was initiated by the consenting process and gathering of demographic data, including a review of the inclusion criteria. The open-ended questions that followed (Appendix A) were designed to explore the relationship between the student and the mentor.

A peer review process was completed prior to piloting the interview guide to establish content validity with three individuals. Each reviewer was selected for a specific reason, but all had basic knowledge of qualitative methods: 1) their expertise in the socialization framework, 2) content expertise in mentoring relationships, and 3) experiences with mentorship while in a doctoral program. Grammatical edits and flow of questions were suggested but no changes were made to the overall protocol. A pilot study was completed with one doctoral student fitting the inclusionary criteria. This was done upon completion of the peer review process. The pilot was conducted to establish flow, interpretability of the questions, and length of the interview session. The pilot study yielded no changes to the interview guide and was thus included in the final presentation of the findings.

\section{Procedures}

Each participant, including the pilot, lasted approximately 40 minutes. All interviews were completed using Zoom video conferencing software (Zoom Video Communications, Inc. San Jose CA, USA), to allow for improved rapport between the researcher and participant, as well as to allow for capture of verbal and non-verbal cues. At the conclusion of the interview, recording ceased, and the audio file was uploaded into a free-online transcription software, Otter Voice Meeting Notes (Otter.ai, Los Altos CA, USA). Transcription files were cleaned of grammatical errors. Field notes were also used during each interview, as it helped capture key aspects of the doctoral students' experiences and reflections and served as support during the analysis process. Upon completion of the transcript and coding, it was determined that more clarification was needed on a couple of findings for one participant; the participant willing added additional information upon request.

\section{Data Analysis}

Data was evaluated and examined using a phenomenological approach, by the lead author. ${ }^{20}$ To begin, the transcriptions were read globally to gain a sense of the data. It was during this process that the field notes were taken to summarize the overall impression captured during the data immersion process by the researcher. The notes were representative of the interpreted meaning of the textual data, as well as key terms to represent the meaning of the experiences shared by the participants. As the coding process continued through "reads" of the transcripts, statements as having meaning, as it pertained to the phenomenon (i.e. mentoring), were identified. These statements were highlighted and then extracted once commonalities were identified among the transcripts. The data that was extracted was then labeled to articulate the global meaning of the data. Figure 1 highlights the labels used to represent the final themes.

\section{Data Credibility}

Credibility was established with three specific mechanisms: 1) research triangulation, 2) bracketing/reflexivity, and 3) peer review. Research triangulation was used to mediate the influences of researcher bias by having multiple opinions and perspectives. From the outset of the study, the research team made decisions regarding data collection. As part of the study's development, each member of the researcher team shared their personal experiences with mentoring and shared their biases (i.e. bracketing). The peer review was conducted in two steps: 1) content review of the interview protocol, as discussed, and 2) evaluation and confirmation of the data analysis process. A peer (not same as 3 included in content review), with a substantial publication record rooted in qualitative research and focus on mentoring reviewed the final themes by examining the several coded transcripts and quotes extracted to support those themes. The peer was not involved with the data collection, which allowed for a more unbiased review of the transcripts and data.

\section{RESULTS}

Three main themes (Figure 1) materialized from the data analysis, including 1) guided autonomy, 2) humanistic nature, and 3) professional advocate. Each theme is defined, narrated, and supported by participant quotes as follows. The figure highlights the codes used to operationally define the themes. The 3 themes are stand-alone, and no sub-themes were identified. 


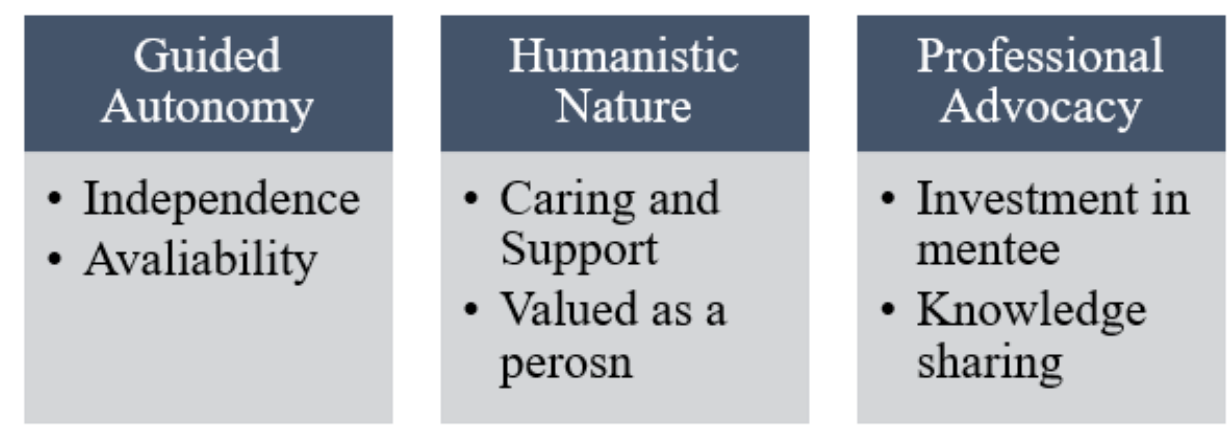

Figure 1. Needs and Preferences of Doctoral Students of their Mentors

\section{Guided Autonomy}

Guided autonomy was operationalized by our participants as the "freedom" to perform within their academic roles, independent of "micromanagement" from their mentor, but with the availability for feedback as well as growth, knowledge, and skill development. Manny discussed the need for "autonomy" from his mentor and described it as belief in the mentee's skills by the mentor, despite the mentee not having the knowledge of skills yet. Manny shared,

I think trust [is important], I guess, trust in [me] like allowing us [as the mentee/student] to kind of take the lead on things. I like, personally, like to learn through experiences. And so, l'd rather kind of make mistakes, my own mistakes.

Manny further explained that in addition to learning autonomy, his mentor was also "willing to be available to you anytime if you need it." Melissa, much like Manny's needs in a mentor, blended the chance to do and try, with the reassurance that the mentor can be there to guide and support. Melissa stated when discussing her needs from a mentor,

Giving me [the mentee] the space to fail but being there so they don't fall flat on their face... giving them the freedom to try things and kind of figure it out, but still have that safety net of at least leading them in the right direction.

Josie described her mentor's style as him being "fairly hands off but can provide really good guidance if need be. He's also very available." When asked to discuss her experiences as a student under her mentor, she continued by sharing

So, if I do have any questions, like I said, I can just pop into his office. But really, the way he kind of structures his mentoring style is to float out a question to kind of think about and then circle back together and look at some resources to kind of think through a problem and then think about ways that things can be addressed through research questions or research studies. So, I'd say, yeah, fairly hands off, but structured at the same time, if that makes sense.

When sharing their definitions of mentorship and their needs from their current doctoral mentors, others used the terms "guidance" or "a guide." For example, Shirley said,

I guess mentorship would be helping someone grow with guidance but also allowing them to have the freedom to realize things on their own. So, kind of like the 'Goldilocks' approach, so you're not too strict and micromanaging but you're also not so loose that you feel like you don't have any direction. It's finding the right balance.

Tim shared his definition of mentorship as "mentorship is someone who would be there at most hours of the day if you had a question. Someone who trusts you enough to let you do things on your own but also someone who's there as a backup if you need help, they're there to give you some guidance." Tim's current mentor displayed this type of mentorship, as he detailed in his interview:

He's a good combination of both hands-off and hands-on, he knows what we do on a daily basis, but he lets you run everything without his guidance. I mean I can go to him with questions, but I try to stick to myself and be independent, but if I do have a technical question he's there. 
Independence and availability were the founding concepts supporting the development of the guided autonomy theme, as our participants wanted to be guided through a hands-off approach but have their mentors available to provide meaningful feedback for continued development towards their career goals.

\section{Humanistic Nature}

Humanistic nature was conceptualized as traits that encompass "caring" and "understanding," which demonstrates an interest in the mentee, as well as a relationship that extends past a professional one, whereby the mentee is viewed as human. Caring and support, along with value as a person were the founding concepts that summarize humanistic nature of the mentee's needs from their mentor. Common words used to describe the mentors were "honest," "direct," "humble," "supportive," "constructively criticizing," "welcoming," "kind", and "positive." Participants described their mentors as "approachable" and having an "open door policy." A few participants also spoke about how their mentors were very inviting and wanting to connect with their mentees. John said, "typically, the door is open. So, it's very inviting and that creates, I think, a really good environment." Melissa also said, "her door is always open" and that her mentor "welcomes us." Participants felt that mentors who are open to their students coming and talking with them have a better relationship.

Participants discussed the importance of feeling valued by their mentor, but also seen as a person not just a professional working towards a goal (i.e. terminal degree). Jason stated, "... you're a human. You're not just a worker." Mentees want their mentors to see them as humans and not just students, which is why they want to be able to have a personal relationship along with their professional one. John mentioned, "I feel like she knows me on both levels" when talking about relationships being professional and personal. He continued, "She's capable of distinguishing those different roles and is able to give me, I think, the appropriate, like feedback or advice or guidance based on whatever it is that l'm asking or seeking." Another participant spoke similarly about the mentor knowing them on both personal and professional levels. Tyler said that he has the ability to talk to his mentor about things that aren't work related and that his relationship with his mentor is both personal and professional. He went on to say,

My mentor and I frequently get lunch or dinner together and with our families. Our spouses are friends. This type of relationship is absolutely important to me in a mentor. It helps both of us gain perspective about each other.

Humanistic nature was defined by two main components: first, having a mentor that demonstrates an interest in the mentee through an approachable personality; and second, a relationship between the mentor and the mentee being built on not just a professional level, but a personal one as well.

\section{Professional Advocate}

Being a professional advocate was defined as having the experience necessary to help the mentee reach their professional goals, as well as the interest in conveying this experience to the mentee. During his interview, Tim discussed his mentor's commitment to "teaching him" on various aspects of a grant they were working on. He discussed the "dedication and devotion he showed me, while working on the project." He continued that his mentor was "very generous of his time." Tim recognized that he was able to learn a lot from his mentor, as he "has devoted a lot of time to his academic research and analyzing and presenting his data. It is really cool that he can just talk science with me and can share his experience." Tim felt that his mentor's experiences and current research allowed him to "collaborate on many papers, so I can get a diverse publication record." Stella shared that her mentor "really likes to teach, to show, and explain. She also believes in collaborating with me, and we can sit and talk about a topic, and go back and forth. I have learned a lot from her, through her experience, guidance, and interest in my development." Josie shared a very positive relationship with her mentor: "He really wants me to pursue my path that I want to [take], but he can guide me in the right path, as he has the experience and knowledge on his end." As she continued to describe her views on mentorship Josie continued, "he's really good at letting me explore on my own, to create my own path, but then he's good at taking that idea, because of his own ideas and path, and getting me to think about it in a different way."

Melissa talked about the support her mentor gave, working towards her degree, as her mentor ensured her curriculum vitae (CV) was representative of the skill sets she would need to succeed. She shared,

"He's supported my growth, and what I am interested in. He is making sure that by the time I leave here with my PhD, that I have a CV that demonstrates the [teaching \& research] skills I need to be successful in the future."

Tim shared the importance of his mentor having a scholarly record (e.g. publications, presentations at conferences), as it would translate to his success as he worked towards his professional goals. Tim said of his mentor who had the knowledge and experience, "he's an advocate of my career and takes you to meetings, introduces you to people, and they're just a major advocate for you." Katie explained that her mentor is 
"well-known" in her field, which translated to professional opportunities. She shared about how she sought out her mentor, "I needed them [a potential mentor] to be a well-known person in their field because that's what I'm trying to prove, expand, or get a lot of opportunities in my field. I think for me, I need someone who's very invested in their current field and topic and can boost my career."

Katie has been able to receive that professional advocacy and professional development from her mentor thus far in her studies. Investment and knowledge sharing conceptualized professional advocacy as described by our participants.

\section{DISCUSSION}

Mentoring is a key aspect of doctoral education, as it provides the student a chance to be acclimated into their future role as a faculty member through engagement in active learning. Conceptually, there is an understanding that mentoring at the doctoral level is rooted in guidance, which is focused on an induction process that can prepare the student to successfully enter an academic or research community. The mentoring relationship must be effective to allow this to successfully happen. Thus, as the student (i.e. the mentee) is the beneficiary of this experience, it is important to understand what they need from their mentors while engaged in doctoral education. Our results suggest that doctoral students are looking for a mentor that blends both career/academic and psychological functions, as they navigate their socialization process and acquire the necessary knowledge, skills, and experiences for success. Specifically, they are looking for a blend of relational and personal attributes in their mentors. Relationally speaking, they want a mentor to guide them through professional experiences autonomously with feedback, as well as display interpersonal skills such as being approachable and humanistic.

\section{Guided Autonomy}

The concept of guided autonomy aligns with the idea of andragogy, whereby adult learners benefit most from engaging in learning activities that can be self-directed and apply to real-life. ${ }^{21}$ Our participants were internally motivated to learn and wanted their mentors to provide them with independent learning opportunities that would facilitate skill and knowledge acquisition that would directly translate to the future, a foundational component to andragogy. ${ }^{21}$ Past literature has demonstrated a doctoral student's desire to have a mentor who demonstrates professional development through autonomy. ${ }^{5}$ The idea of autonomy not only supports adult learning principles (i.e. andragogy), it also authenticates the need to feel trusted by a mentor. Trust has been widely reported as a necessary attribute of a mentor and when a mentee is given autonomy over their work, trust is therefore implied. 5,11,22

A key aspect to our study's findings is our participants' desire for a mentor who is available to provide feedback, support, or reassurance in the performance of the student. Similar to trust, availability particularly to provide feedback has been cited as an ideal mentor quality ${ }^{5,11,22}$ Availability to provide feedback grants the mentee with awareness of their performance, and as reported, provides a chance to feel acclimated and legitimized. ${ }^{3}$ Gaining legitimization is important in the socialization process and mentoring relationship as it allows the mentee to gain affirmation that they are acquiring the skills and knowledge necessary to effectively assume their intended role.

\section{Humanistic Nature}

A humanistic nature is a large overarching concept that speaks to interpersonal attributes that make a mentor relatable, more human, and approachable. Past literature has used the term "humanistic attributes" to describe ideal mentors., ${ }^{8,23,24}$ For our cohort of doctoral students, the idea of a humanistic approach/nature was embodied by a mentor who demonstrated an investment in the doctoral student themselves, beyond the professional role they were assuming in their mentor relationship. This was displayed by caring qualities, showing interest, and providing them with support which was demonstrated by being available and welcoming to the student. Our participants felt they had a mentor relationship that was both professional and personal, making the mentor more relatable and approachable. The mentoring relationship is dynamic and constantly evolving, therefore, as the relationship grows it is likely that so does the collegiality between the pair. Ideally, effective mentor relationships grow into lifelong partnerships, so having a more personable relationship is important.

Kram, a pioneer in the mentoring literature, first described the psychological function of the relationship as one that can be forged into friendship, which would indicate the mentor would need to show interest in the mentee beyond the student needing to learn the ropes..$^{12}$ Our participants wanted to feel valued by their mentors and be able to relate to them as humans. The psychological component of a mentoring relationship is grounded in the idea that the relationship offers relatability, interest, and emotional support that can extend beyond work roles.18,25 Our findings from an individual perspective mirror those of Clarke et al, as they reported that doctoral mentees placed great emphasis on the psychological functions of mentoring. ${ }^{16}$ 


\section{Professional Advocacy}

Our participants described needing their mentors to be professional advocates, which is similar to the "induction" attribute described by the conceptual model developed by Yob and Crawford. ${ }^{15}$ The attribute of professional advocacy speaks to the need of the mentor to support the professional development of the mentee related to their future, new professional role. 5,15 Mentors have been described as teachers. and our participants shared how their mentors were invested in sharing their knowledge and experiences as a way to ensure they were acclimated and eventually "inducted" into their future professional role. Furthermore, our participants described an investment of their mentor's time into their professional development through meetings, informal teaching sessions, and feedback on tasks completed (i.e. grant writing, papers, etc.). The mentoring relationship is a time investment for both parties; however, at certain time points, a mentor must be willing, engaged, and available to support the mentee. $5,24,26$ In fact, perceptions of interest, availability, and investment have been directly linked to higher levels of satisfaction with mentoring relationships. ${ }^{16}$ For the doctoral student, the perception of investment is of utter importance, as they view the mentoring relationship as the conduit to their future roles as a member of the higher education community, and place great emphasis on its merit. ${ }^{27}$

\section{Future Directions and Limitations}

Our study examined mentorship from the perspective of the mentee, only. Although it is important to understand the needs of the mentee in the mentor relationship, the perspective of the mentor can only extend the full understanding and appreciation of the complexity of the relationship. Future research should examine the perspective of the mentor, as well as the mentor-mentee pair in the same study. Moreover, gaining a better appreciation of the background of the mentor, as in terms of training received to be a mentor, among other experiences that prepared them to mentor should be helpful in gaining a full understanding of the mentorship relationship. While qualitative research is based upon a small number of participants, we recognize this sample only represents the small number of doctoral students pursuing academic degrees within those academic curriculums offering content in exercise science, rehabilitative exercise, athletic training, and allied health. Future studies should extend the work to other disciplines to understand how mentorship occurs, independent of content of the curriculum. Furthermore, several reliable scales exist to assess the quality of the relationship, as well as ideal attributes of a mentor. To support our findings, other studies should look to use a mixed methods approach. Our sample also only included those doctoral students who were employed in a graduate assistantship role, which could impact the mentoring relationship on some level; thus, future studies should examine online doctoral programs, as well as those programs that can be completed independent of an assistantship.

\section{CONCLUSIONS}

Mentoring is an important part of doctoral education, as the mentor serves as the conduit for the student to learn more about the research and academic community they soon intend to assume. There is an abundance of literature on mentorship, and our findings are able to contribute uniquely yet complimentarily. Doctoral students enrolled in exercise science and allied health related programs are looking for their mentors to demonstrate a blend of relational and personal attributes during their educational experiences. These attributes are founded on professional guidance and advocacy, feedback, and being human.

\section{References}

1. Tierney WG, Rhoads RA. Enhancing Promotion, Tenure and Beyond: Faculty Socialization as a Cultural Process. ASHE-ERIC Higher Education Report No. 6. ERIC; 1993.

2. Menges R. Faculty in New Jobs: A Guide to Settling In, Becoming Established, and Building Institutional Support. Jossey-Bass Higher and Adult Education Series. ERIC; 1999.

3. Klossner J. The role of legitimation in the professional socialization of second-year undergraduate athletic training students. Journal of Athletic Training. 2008;43(4):379-385.

4. Young A, Klossner J, Docherty CL, Dodge TM, Mensch JM. Clinical integration and how it affects student retention in undergraduate athletic training programs. Journal of athletic training. 2013;48(1):68-78.

5. Mazerolle SM, Bowman TG, Klossner JC. An analysis of doctoral students' perceptions of mentorship during their doctoral studies. Athletic Training Education Journal. 2015;10(3):227-235.

6. Pitney WA, Ehlers GG. A grounded theory study of the mentoring process involved with undergraduate athletic training students. Journal of Athletic Training. 2004;39(4):344.

7. Pitney WA, Ilsley P, Rintala J. The professional socialization of certified athletic trainers in the National Collegiate Athletic Association Division I context. Journal of Athletic Training. 2002;37(1):63.

8. Pitney WA EG, Walker SE. A descriptive study of athletic training students' perceptions of effective mentoring roles. . Internet J Allied Health Sci Pract. 2006;4(2):1-8.

9. Gruber J, Borelli JL, Prinstein MJ, et al. Best practices in research mentoring in clinical science. Journal of Abnormal Psychology. 2020;129(1):70. 
10. Bell-Ellison BA, Dedrick RF. What do doctoral students value in their ideal mentor? Research in Higher Education. 2008;49(6):555.

11. Johnson WB. Are advocacy, mutuality, and evaluation incompatible mentoring functions? Mentoring \& Tutoring: Partnership in Learning. 2008;16(1):31-44.

12. Garvey B, Alred G. An introduction to the symposium on mentoring: Issues and prospects. British journal of guidance and counselling. 2003;31(1):3-9.

13. Burningham DS, Deru L, Berry DC. What traits make for an effective athletic training educator and mentor? Athletic Training Education Journal. 2010;5(4):183-186.

14. Kram K. Phases of the mentor relationship. Academy of Management Journal (pre-1986). 1983;26(4):608.

15. Yob IM, Crawford L. Conceptual framework for mentoring doctoral students. 2012.

16. Rose G. Enhancement of Mentor Selection Using the Ideal Mentor Scale. Journal of the Association for Institutional Research. 2003;44(4):473-494.

17. Nottingham SL, Mazerolle SM, Barrett JL. Roles of mentoring for novice athletic training faculty members. Athletic Training Education Journal. 2017;12(4):234-243.

18. Clark RA, Harden SL, Johnson WB. Mentor relationships in clinical psychology doctoral training: Results of a national survey. Teaching of psychology. 2000;27(4):262-268.

19. Pitney WA, Parker J., Singe, S.M., Potteiger, K. Qualitative Reserach in the Health Professions. 1 ed: SLACK, Inc.; 2020.

20. Creswell JW. Qualitative Inquiry \& Research Design Choosing Among Five Approaches. Sage Publications. Thousand Oaks, CA. 2007.

21. Knowles MS. The making of an adult educator: An autobiographical journey. Jossey-Bass Inc Pub; 1989.

22. Sambrook S, Stewart J, Roberts C. Doctoral supervision... a view from above, below and the middle! Journal of Further and Higher Education. 2008;32(1):71-84.

23. Barrett JL, Mazerolle SM, Nottingham SL. Attributes of effective mentoring relationships for novice faculty members: perspectives of mentors and mentees. Athletic Training Education Journal. 2017;12(2):152-162.

24. Nottingham SL, Mazerolle SM, Barrett JL. Effective characteristics of formal mentoring relationships: the National Athletic Trainers' Association Foundation research mentor program. Athletic Training Education Journal. 2017;12(4):244-255.

25. Blake-Beard S, Bayne ML, Crosby FJ, Muller CB. Matching by race and gender in mentoring relationships: Keeping our eyes on the prize. Journal of Social issues. 2011;67(3):622-643.

26. Ragins BR, Cotton JL, Miller JS. Marginal mentoring: The effects of type of mentor, quality of relationship, and program design on work and career attitudes. Academy of management journal. 2000;43(6):1177-1194.

27. Austin AE. Preparing the next generation of faculty: Graduate school as socialization to the academic career. The journal of higher education. 2002;73(1):94-122.

\section{APPENDIX: Interview Guide}

\section{DEMOGRAPHIC INFORMATION}

1. What is your age?

2. What is your Gender?

3. What are your preferred pronouns?

4. What is your race?

5. What was your undergraduate major?

6. What was your master's degree?

7. What is the name of your current institution?

8. What academic doctorate are you pursuing, $\mathrm{PhD}$ or EdD?

a. Probe: What will your doctorate be in? (e.g. Kinesiology, Physical Therapy, Athletic Training, etc.)

9. How many semesters have you completed in your program?

\section{OPEN ENDED}

a. What year are you in your $\mathrm{PhD} / \mathrm{EdD}$ ?

10. Describe your educational journey for me?

a. Probe: (general timeline, undergraduate degree-now)

11. Do you hold any credentials?

a. Probe: These include credentials such as: Certified Strength and Conditioning Specialist, Athletic Trainer, Exercise Physiologist... etc. 
12. What type of graduate assistantship do you have?

a. Probe: Is it full time or part time?

13. How do you define "mentorship"?

14. Have you had mentors in the past?

15. How many overall mentors have you had in your educational journey?

a. Probe: How many of these mentoring relationships do you currently continue

b. Probe: Do any of your mentors hold terminal degrees, such as a PhD or EdD?

16. What types of roles were those individuals serving?

a. Probe: Academic, Clinical, etc.

17. Do you currently have a mentor?

a. Probe: Is your current mentor your academic advisor?

18. What is the sex of your current mentor?

19. How long has your mentor been at their university/institution?

a. Probe: Are they tenured faculty?

20. How frequently do you meet with your doctoral mentor?

a. Probe: Can you describe the method in which those meetings happen? (texting, phone calls, etc.)

21. How would you describe your relationship with your current mentor?

a. Probe: Is the relationship strictly professional or is it both professional and personal?

b. Probe: Do you have the ability to talk about things that are not work related?

22. What top 5 attributes do you see/need in a mentor?

a. Probe: Would you say that your current mentor encompasses all of those?

23. How would you describe their mentoring style?

24. How have you developed your professional identity during your tenure as a doctoral student?

25. In your educational training can you describe a mentoring experience that had an impact on you (negative or positive) and how that influences your need for mentorship today?

26. Have you had any experiences serving as a mentor?

a. In what capacity? 